\title{
An Examination of Concussion Injury Rates in Various Models of Football Helmets in NCAA Football Athletes
}

\author{
Ryan Moran and Tracey Covassin \\ Department of Kinesiology, Michigan State University, East Lansing, MI 48824, USA
}

\begin{abstract}
While newer, advanced helmet models have been designed with the intentions of decreasing concussions, very little research exists on injury rates in various football helmets at the collegiate level. The aim of this study was to examine concussion injury rates in various models of football helmets in collegiate football athletes. In addition, to compare injury rates of newer, advanced football helmets to older, traditional helmets among collegiate football athletes, a total of 209 concussions and 563,701 AEs (athlete-exposures) among 2,107 collegiate football athletes in seven helmet models were included in the analyses. Concussion injury rates revealed that the Riddell Revolution ${ }^{\circledR}$ had the highest rate of 0.41 concussions per 1,000 AEs. The Schutt ION $4 \mathrm{D}^{\mathrm{TM}}$ helmet had the lowest rate of 0.25 concussions per 1,000 AEs. These newer helmet models did not significantly differ from one another $(P=0.74)$, however, all models significantly differed from the older, traditional helmet model $(P<0.001)$. The findings of this study suggest that concussion rates do not differ between newer and more advanced helmet models. More importantly, there are currently no helmets available to prevent concussions from occurring in football athletes.
\end{abstract}

Key words: Football (American), concussion, injury rates, helmets.

\section{Introduction}

There are approximately 1.6 to 3.8 million sport-related concussions each year in the United States, with football resulting in one of the highest prevalence of concussion [1-3]. The incidence of concussion in NCAA (National Collegiate Athletic Association) football athletes is from 0.37 to 0.74 per 1,000 AEs (athlete-exposures) [2-7]. While manufacturers of football helmets are reluctant to claim that one football helmet model is better at preventing concussions than another, there is still a lack of research to deem one helmet better than another. Football helmets are designed to mitigate the likelihood of head injuries from an impact to the head by dissipating and distributing the energy of the impact and protecting the head from penetration. Early football helmets were designed to prevent skull fractures as well as moderate to severe brain injuries such as swelling and hemorrhaging [8-10]. However,

Corresponding author: Ryan Moran, M.S., ATC, instructor, research field: sport-related concussion. E-mail: moranry3@msu.edu. there is limited evidence from epidemiological and biomechanical studies that current football helmet designs reduce the risk of sports-related concussion [3]. With the transition from older, traditional helmet models to the newer, advanced helmet models, the intention is to help reduce the likelihood of concussions. These newer, advanced models are designed for the energy attenuation, size, mass, comfort and safety. The goal of the attenuation is to decrease the peak deceleration and increase the time duration over which the deceleration occurs, thus sparing the athlete of more impact [11]. However, the majority of the research in these newer football helmets has focused on head impacts and has primarily only used high school and professional football athletes [12-14]. There has been little to no research studying concussion injury rates in various football helmets among NCAA football athletes.

In the late 20th century, Riddell, a leading manufacturer of protective sports equipment, developed the Revolution ${ }^{\circledR}$ model football helmet. The Revolution ${ }^{\circledR}$ was designed to not only better protect the 
head from skull fractures, but aimed at reducing concussions. To test this hypothesis, Collins et al. [15] compared concussion rates and recovery time in high school football athletes wearing the Revolution ${ }^{\circledR}$ and a traditional football helmet (i.e., Riddell ${ }^{\circledR}$ VSR4). Collins and colleagues reported a $31 \%$ decrease in relative risk of concussions in athletes wearing a Revolution ${ }^{\circledR}$ model as compared to a traditional model. However, the percentage of total concussions in athletes wearing the Revolution ${ }^{\circledR}$ model was $5.3 \%$, while athletes wearing the standard helmet were $7.6 \%$, suggesting that these findings were not very robust. Moreover, this study only examined high school athletes and not NCAA athletes.

The NOCSAE (National Operating Committee on Standards for Athletic Equipment) performs a series of drop tests to certify and assess football helmet's ability to prevent skull fractures. While football helmets have been designed and manufactured to meet the NOCSAE standards, these standards do not consider concussions or concussion rates. As a result, NOCSAE and helmet manufacturers have been reluctant to claim that a single model or brand of helmet is better at preventing concussions. As helmet technology became more advanced, an evaluation system was developed to assess head impact exposure and concussion risk [16]. The STAR (summation of tests for the analysis of risk) evaluation system created a rating scale for 15 adult football helmets available to consumers. That STAR rating system ranged from one to five stars based off their STAR values to indicate their ability to reduce concussion risk. The STAR rating was assessed mechanically using a series of drop tests to determine impacts. A five-star rating indicates the best available football helmet at reducing concussions, with a one star considered marginal at reducing concussions.

Due to the absence of comparative data with concussion injury rates between helmet manufacturers and models, and a lack of studies conducted measuring concussion injury rates in collegiate athletes, this study examined concussion injury rates in various models of football helmets in NCAA collegiate football players. In addition, this study also compared injury rates of newer, advanced football helmets to an older, traditional helmet among NCAA football athletes. It was hypothesized that there would be no difference between newer advanced football helmets. However, it was hypothesized that newer, advanced football helmets would have decreased concussion rates compare to the traditional Riddell ${ }^{\circledR}$ VSR4 helmet.

\section{Methods}

\subsection{Participants}

Two thousand one hundred and seven NCAA football athletes from seven participating universities were included in this study (age $=20.2 \pm 1.5$ years, height $=185.2 \pm 9.3 \mathrm{~cm}$, mass $=102.1 \pm 19.8 \mathrm{~kg}$ ). Of the seven participating universities, four universities were from the FBS (Football Bowl Subdivision) and three universities from the FCS (Football Championship Subdivision). The Institutional Review Board approved the study as exempt status due to unidentifiable data.

\subsection{Operational Definitions}

\subsubsection{Concussion}

Concussion was operationally defined as "a complex pathophysiological process affecting the brain, induced by traumatic biomechanical forces" [17]. Only concussions that presented with signs and symptoms (i.e., headache, dizziness, cognitive impairment) as determined by a certified athletic trainer or team physician, were included in the study.

\subsubsection{Athlete Exposure}

An AE (athletic exposure) was defined as one athlete participating in one game or practice, where the athlete is exposed to the possibility of sustaining an injury [18]. For example, if an NCAA football team has 100 athletes that take part in 5 days of practice in a given week, that team has $500 \mathrm{AEs}$ for the week. Athletic trainers at each institution were responsible for entering in the AEs. 


\subsubsection{Helmet Models}

The newer, advanced helmet models represented in this study were the Riddell Revolution ${ }^{\circledR}$, Revolution $\mathrm{IQ}^{\mathrm{TM}}$, Revolution ${ }^{\circledR}$ Speed, Schutt AiR XPTM, DNA Pro+TM, and ION 4D ${ }^{\mathrm{TM}}$. The traditional helmet model was the Riddell ${ }^{\circledR}$ VSR4 due to its use prior to the newer, advanced models and now having limited energy attenuation capabilities and using only a fitting device called a "jaw pad" below the ear [15]. In addition, this was the helmet used as the traditional helmet in the Collins and colleagues study [15].

\subsection{Procedures}

The data used for this study were collected over a period of four years (2009-2012) using the SIMS (Sports Injury Monitoring System), a database application for injury management and documentation that is certified for use with the NCAA Injury Surveillance Program. An email was sent to the company that owns SIMS, asking to send an email to the head athletic trainers at the universities that use the injury monitoring system asking for their participation. Unfortunately, the researchers were not permitted to know the total number of head athletic trainers that received the email from the SIMS company. Head athletic trainers who agreed to participate in the study asked the equipment manager for helmet models used each year and entered the information into SIMS. Athletic trainers then exported the following data from SIMS: AEs, date of birth, height, weight, football playing position, helmet model used per season, and concussion year (if one had occurred). The excel spreadsheet was then sent to the research team.

\subsection{Statistical Analyses}

Data were analyzed using descriptive and inferential statistics. An IR (injury rate) is a statistical measure describing the number of injuries to the number of AEs, multiplied by a reference population of 1,000 AEs [19]. Injury rates were calculated using the following formula: [\# concussions per helmet model] / [ $\sum \mathrm{AE}$ per helmet model] $\times 1,000$ AEs. A chi-square test of homogeneity was conducted to determine if the newer, advanced helmet models differed from one another. A poisson regression was conducted to determine if these newer, advanced helmet models differed from the Riddell ${ }^{\circledR}$ VSR4 traditional helmet model. To adjust for exposure differences, the AEs of each helmet were used as a weight variable in the generalized linear model analysis. SPSS version 21.0 was used to perform all statistical analyses. The level of significance was set a priori at $P<0.05$.

\section{Results}

Over the four-year period, there were a total of 563,701 AEs and 209 concussions, producing an injury rate of 0.37 concussions per 1,000 AEs. Offensive lineman sustained the most concussions $(n=36,17.2 \%)$ followed by linebackers $(n=34,16.3 \%)$ and wide receivers $(n=30,14.3 \%)$. Quarterbacks sustained the least amount of concussions $(n=9,4.3 \%)$. However, these were total number of concussions and did not take into consideration AEs for each position. Breakdowns of concussions by position are presented in Table 1.

The helmet models included in the analyses consisted of the Riddell Revolution ${ }^{\circledR}$, Revolution IQ ${ }^{\mathrm{TM}}$, Revolution ${ }^{\circledR}$ Speed, Schutt AiR XPTM, DNA Pro+TM and ION 4D ${ }^{\mathrm{TM}}$. The Riddell Revolution ${ }^{\circledR}$ had the highest injury rate at 0.41 concussions per 1,000 AEs followed by the Schutt DNA Pro+TM at 0.37 concussions per 1,000 AEs (Table 2). The Schutt ION

Table 1 Total concussions by football position.

\begin{tabular}{ll}
\hline Position & No. of concussions \\
\hline Offensive lineman & $36(17.2 \%)$ \\
Linebackers & $34(16.3 \%)$ \\
Wide receivers & $30(14.3 \%)$ \\
Defensive backs & $29(13.8 \%)$ \\
Defensive lineman & $26(12.4 \%)$ \\
Running backs & $25(11.9 \%)$ \\
Tight ends & $13(6.2 \%)$ \\
Quarterbacks & $9(4.3 \%)$ \\
Uncategorized & $7(3.3 \%)$ \\
\hline
\end{tabular}


Table 2 Athlete exposures and injury rates for new, advanced helmet models.

\begin{tabular}{lllllll}
\hline Helmet & No. in use & No. of A-E & No. of concussions observed & No. of concussions expected & Injury rate $^{*}$ & Significance $^{\dagger}$ \\
\hline Revolution & 442 & 113,975 & 47 & 40.35 & 0.41 & 0.001 \\
DNA Pro+ & 234 & 60,975 & 23 & 10.74 & 0.37 & 0.001 \\
AiR XP & 78 & 30,320 & 11 & 15.60 & 0.36 & 0.001 \\
Revo IQ & 269 & 62,206 & 22 & 22.02 & 0.35 & 0.001 \\
Speed & 764 & 230,752 & 78 & 81.70 & 0.34 & 0.001 \\
ION 4D & 185 & 44,037 & 11 & 21.59 & 0.25 & 0.001 \\
\hline
\end{tabular}

Injury rate per 1,000 athlete-exposures.

${ }^{\dagger} P$-values $<0.05$, significantly different than traditional helmet Riddell ${ }^{\circledR}$ VSR4.

$4 \mathrm{D}^{\mathrm{TM}}$ was the model with the lowest injury rate $(0.25$ concussions $/ 1,000$ AEs) followed by the Riddell Revolution ${ }^{\circledR}$ Speed at 0.34 concussions per 1,000 AEs. A chi-square test for homogeneity indicated that there were no statistically significant differences between the six newer, advanced helmet models $\left[\chi^{2}=2.718, P=\right.$ 0.74]. A poisson regression was conducted and weighted by AE. Our results revealed that all six newer, advanced helmet models were significantly different from the traditional helmet $(P<0.001)$. The Riddell ${ }^{\circledR}$ VRS4 had a significantly higher concussion injury rate than all of the newer, advanced Riddell and Schutt models used in this study (Table 2).

\section{Discussion}

To our knowledge, this is the first study to examine concussion injury rates among newer football helmet models in NCAA football athletes. First, our injury rate of 0.37 concussions per 1,000 AEs is consistent with Hootman et al. [2] and Dick et al. [5] who reported identical injury rates of 0.37 per 1,000 AEs, as well as other studies reporting rates between 0.37 and 0.74 concussions per 1,000 AEs $[4,6,7]$. The main findings from this study suggest that there are no differences in concussion injury rates among newer, advanced models of football helmets. However, we did find that newer more advanced football helmets had significantly lower concussion injury rates than the traditional helmet, the Riddell ${ }^{\circledR}$ VRS4. The results of our study are similar to Collins and colleagues [15] who reported a decreased relative risk while wearing the Revolution ${ }^{\circledR}$ helmet. The Revolution ${ }^{\circledR}$ did, however, have the highest injury rate at 0.41 concussions per 1,000 AEs, although not significant compared to the other newer football helmets.

While we did not find any significant difference between these models, Rowson and Duma [16] created an evaluation system to rate both traditional and newly designed football helmets. This rating system was based off of their head impact exposure and risk for concussion criteria. Rated on a one- to five-star scale, with a five-star rating indicating that it is the "best available helmet", four stars indicating the helmet is "very good", three stars indicating a "good" helmet, two stars were "adequate", and one star as "marginal". The five-star helmets included the Riddell Revolution ${ }^{\circledR}$ Speed, which had our second lowest concussion injury rate. The four-star helmets included in this study were the Schutt ION 4D ${ }^{\mathrm{TM}}$, Riddell Revolution ${ }^{\circledR}$ and Revolution ${ }^{\circledR}$ IQ. While receiving a "very good" four-star rating, the Revolution ${ }^{\circledR}$ appeared to have the highest concussion injury rate in our study, while the Schutt ION $4 D^{\text {TM }}$ had the lowest concussion injury rate. The Schutt DNA $\mathrm{Pro}^{+\mathrm{TM}}$ and Schutt AiR XPTM received a three-star rating, while the lone one-star helmet, the Riddell $^{\circledR}$ VSR4 was the reference traditional helmet for our study. The STAR rating study lacked good biomechanical data, due to only testing "helmet to ground" impacts with linear acceleration. The risk for concussions in football also arises from "helmet to helmet" impacts, as well as a rotational acceleration component. Undoubtedly, football helmets do reduce the number of skull fractures in football players, which they were designed 
to do, but the debate still continues as to whether or not these newer and more technologically improved helmets are doing a better job at protecting the head and reducing the number of concussions. The findings from the current study did not claim that one helmet is better than another at reducing and preventing concussions, as no football helmet is currently available to completely eliminate concussions.

This study was not without limitations. Our study only examined helmet models from Riddell and Schutt, excluding other brands such as Xenith and Rawlings, due to either low numbers of concussions or no athletes in their helmet models. Additionally, due to low number of concussions and AEs for football helmets and concussion information being exported by year, we combined AEs for practices and games. The current study only examined concussion injury rates and not other variables such as previous history of concussion, mechanism of injury, location of injury, or head impact. Finally, we did not take into consideration age of football helmet and previous history of concussion. However, collegiate helmets in this study were either reconditioned every year or athletes wore a new helmet every year.

While past literature has encompassed a wide range of populations from high school to professional athletes, it would be beneficial to examine concussion injury rates in youth football helmet models. Recently, helmet manufactures have begun to market to youth football athletes, however, youth football helmets are adult helmets scaled down to fit youth athletes. With a wider array of youth football helmets available and the growing concern for the safety of youth football athletes, more research is needed on these youth football helmets. Improved biomechanical tests and analyses may be of added importance in determining the quality of helmet models. Field performance data are also needed to supplement the laboratory tests that are being conducted. Field testing, including impact and accelerometer data, would be able to better simulate the complex interaction that occurs between the athlete, equipment, and environment at the time that the athlete sustains a concussion. These factors may also be evaluated over a single or multiple seasons, which may also be pivotal in understanding the risk for concussion. The implementation of these types of studies and our own play a critical role in making major steps in the protection and safety of our athletes at all levels of competition.

In conclusion, our results indicate that there were no differences in concussion injury rates between the current football helmet models, however, these newer helmet models appear to be significantly different from the traditional Riddell ${ }^{\circledR}$ VSR4 model. No helmet is currently available to prevent concussions from occurring, though strides are being taken with equipment manufacturers and clinical management by athletic trainers, physicians, researchers and other medical healthcare professionals.

\section{References}

[1] Daneshvar, D., Nowinski, C., McKee, A., and Cantu, R. 2011. "The Epidemiology of Sport-Related Concussion." Clinical Journal of Sports Medicine 30 (1): 1-17.

[2] Hootman, J., Dick, R., and Agel, J. 2007. "Epidemiology of Collegiate Injuries for 15 Sports: Summary and Recommendations for Injury Prevention Initiatives." Journal of Athletic Training 42 (2): 311-9.

[3] Langlois, J., Rutland-Brown, W., and Wald, M. 2006. "The Epidemiology and Impact of Traumatic Brain Injury." Journal of Head Trauma Rehabilitation 21 (5): 375-8.

[4] Booher, M., Wisniewski, J., Smith, B., and Sigurdsson, A. 2003. "Comparison of Reporting Systems to Determine Concussion Incidence in NCAA Division I Collegiate Football." Clinical Journal of Sports Medicine 13 (2): 93-5.

[5] Dick, R., Ferrara, Agel, J., Courson, R., Marshall, S., Hanley, M., and Reifsteck, F. 2007. "Descriptive Epidemiology of Collegiate Men's Football Injuries: National Collegiate Athletic Association Injury Surveillance System, 1988-1989 through 2003-2004." Journal of Athletic Training 42 (2): 221-33.

[6] Gessel, L., Fields, S., Collins, C., Dick, R., and Comstock, D. 2007. "Concussions among United States High School and Collegiate Athletes." Journal of Athletic Training 42 (4): 495-503. 
[7] Guskiewicz, K., Weaver, N., Padua, D., and Garrett, W. 2000. "Epidemiology of Concussion in Collegiate and High School Football Players." The American Journal of Sports Medicine 28 (5): 643-50.

[8] Cantu, R., and Mueller, F. 2003. "Brain Injury-Related Fatalities in American Football, 1945-1999." Neurosurgery 52 (4): 846-52.

[9] Forbes, J., Zuckerman, S., Abla, A., Mocco, J., Bode, K., and Eads, T. 2014. "Biomechanics of Subdural Homorrhage in American Football: Review of the Literature in Response to Rise in Incidence." Child's Nervous System 30 (2): 197-203.

[10] Forbes, J., Zuckerman, S., He, L., McCalley, E., Lee, Y., Solomon, G., Halstead, P., and Sills, A. 2013. "Subdural Hemorrhage in Two High-School Football Players: post-Injury Helmet Testing." Pediatric Neurosurgery 49 (1): 43-9.

[11] IOM (Institute of Medicine) and NRC (National Research Council). 2013. Sports-Related Concussions in Youth: Improving the Science, Changing the Culture. Washington, DC: The National Academies Press.

[12] Pellman, E., and Viano, D. 2006. "Concussion in Professional Football: Summary of the Research Conducted by the National Football League's Committee on Mild Traumatic Brain Injury." Neurosurgical Focus 21 (4): E12.

[13] Pellman, E., Viano, D., Withnall, C., Shewchenko, N., Bir, C., and Halstead, P. 2006. "Concussion in Professional Football: Helmet Testing to Assess Impact
Performance-Part 11." Neurosurgery 58 (1): 78-96.

[14] Viano, D., Pellman, E., Withnall, C., Shewchenko, and N. 2006. "Concussion in Professional Football: Performance of Newer Helmets in Reconstructed Game Impacts-Part 13." Neurosurgery 59 (3): 591-606.

[15] Collins, M., Lovell, M., Iverson, G., Ide, T., and Maroon, J. 2006. "Examining Concussion Rates and Return to Play in High School Football Players Wearing Newer Helmet Technology: A Three-Year Prospective Cohort Study." Neurosurgery 58 (2): 275-84.

[16] Rowson, S., and Duma, S. 2011. "Development of the STAR Evaluation System for Football Helmets: Integrating Player Head Impact Exposure and Risk of Concussion." Annals Biomedical Engineering 39 (8): 2130-40.

[17] McCrory, P., Meeuwisse, W., Aubry, M., Cantu, R., Dvorak, J., Echemendia, R., and Turner, M. 2013. "Consensus Statement on Concussion in Sport: the 4th International Conference on Concussion in Sport Held in Zurich, November 2012." British Journal of Sports Medicine 47: 250-8.

[18] Dick, R., Agel, J., and Marshall, S. 2007. "National Collegiate Athletic Association Injury Surveillance System Commentaries: Introduction and Methods." Journal of Athletic Training 42 (2): 173-82.

[19] National Collegiate Athletic Association. 2000. NCAA Injury Surveillance System for Academic Years 1997-2000. Indianapolis, IN: National Collegiate Athletic Association. 